\title{
Wilderness Restoration: The Paradox of Public Participation
}

\author{
William Throop \\ Philosophy \\ Green Mountain College
}

\author{
Rebecca Purdom \\ Environmental Law and Policy \\ Green Mountain College
}

Wilderness areas often cry out for ecological restoration. Decades of fire suppression, livestock grazing, invasions of exotic species, and recreational impacts have left many U. S. wilderness areas degraded (Cole and Landres, 1996). Frequently ecosystem processes alone are insufficient to ameliorate these problems. As a result, wilderness managers often engage in ecological restoration. Managers are guided by the aims of wilderness preservation ensconced in the U .S Wilderness Act of 1964. These aims are at odds with a movement in the restoration community to increase volunteer participation in projects and to emphasize the human contribution to ecosystem structures. While the Wilderness Act directs managers to minimize the human dimension of ecosystems, proponents of participatory restoration highlight these same elements. The resulting "participation paradox" raises deep issues about the human role in nature, the standards for successful restoration and the traditional conception of wilderness. In this paper, we defend a restrictive account of wilderness that significantly limits restoration activities, and we argue that the norms for successful restoration should be explicitly contextualized to land use designation.

This paper will focus on U.S. wilderness policy, but our thesis applies to any country with wilderness designations that involve similar restrictions on land use. The U.S. Wilderness Act of 1964 characterizes wilderness as areas that are "untrammeled" by humans and that appear to "have been affected primarily by nature, with the imprint of man's work substantially unnoticeable.” Wilderness is to be "managed so as to preserve its natural conditions" and its "wilderness character." We follow Cole (2000) in using the term "wild" to refer to the value associated with the quality of being untrammeled, that is, being relatively uncontrolled and unmanipulated by humans. In contrast, an ecosystem is "natural" to the extent that it has the composition, structure and functions it would have had in the absence of human alterations. ${ }^{2}$

\footnotetext{
${ }^{1}$ Wilderness Act, Public Law 88-577, $88^{\text {th }}$ Congress, $2^{\text {nd }}$ session, September 3, 1964 codified at U.S. Code 16 (2000), 11311136.

${ }^{2}$ See also Graber (2003). Cole (2000) and others define natural in terms of lack of “post-aboriginal” human alterations, but it is hard to see why modern Euro-American alterations are unnatural while sometimes extensive alterations by Native Americans would be natural. Arguably, this view involves a kind of ethnocentrism. It should not matter which humans
} 
The twin charges to maintain an untrammeled landscape and to manage for natural conditions often conflict when areas are degraded and ecological restoration is required. Many restoration projects aim at increasing naturalness by eliminating some noticeable human impacts or reintroducing a missing element of the ecosystem. However, if such management activities involve enough human alteration and control of a system then, arguably, they trammel an ecosystem. A project that would require extensive and long-term use of heavy machinery to restore and maintain populations of native species in their historical distributions might be justified on the grounds that it increased naturalness, but would violate the Wilderness Act's requirement that wilderness lands be untrammeled. Whether an area is trammeled depends on the duration, the spatial extent and the impact of the human activities.

Many management projects involve controlling an area. As a result, some wilderness advocates see a tension between the constraints on human activity associated with wilderness and traditional land management activities. Some have termed this "the paradox of wilderness management" (Hendee and Dawson, 2002; Cole 1995; Turner, 1996; Jordan, 2003). ${ }^{3}$ Since the Wilderness Act imposes a duty to manage wilderness, it cannot be saying that all management constitutes a trammel. Some short-term restoration projects, such as introducing wolves to Yellowstone, involve relatively little direct control over ecosystem processes. Consequently, ecological restoration does not always create a paradox for wilderness managers.

Where managers cannot jointly satisfy the naturalness and wildness conditions in a wilderness restoration project, they must either compromise both aims or pursue one to the detriment of the other. It is hard to tell how frequently such conflicts arise. Both wildness and naturalness are matters of degree, and there are no clear thresholds where a certain degree of control becomes a trammel or a degree of human alteration makes an ecosystem unnatural. ${ }^{4}$ Cole (2000) suggests that these conflicts are sufficiently common that we should decide to manage some wilderness areas for naturalness and

alter a system, but it does matter how long ago the alterations occurred, for natural processes may wash humanization out of a system.

${ }^{3}$ This is not a paradox in the standard philosophical sense of the term, viz., a set of propositions which are all intuitively plausible but which cannot all be true. The management paradox is a group of values or guidelines that enjoin conflicting behaviors. Values that cannot be mutually satisfied can still be truly valuable. We will follow Hendee and others in using the looser sense of "paradox."

${ }^{4}$ Decisions about when to restore are further complicated by issues about what temporal scales are relevant to assessing when restoration trammels an area. For example, should we worry about a short-term trammel if the result is a much higher degree of naturalness in the long term? 
others for wildness. In the former, restoration could be quite extensive, while in the latter it would be restricted to projects involving minimal control, e.g. hand pulling a few exotic plants.

The above management paradox becomes more intractable in the light of current developments in ecological restoration. Much recent work in restoration theory has urged that good restoration must involve extensive participation by volunteers, each playing a role in manipulating the ecosystem (Higgs, 2003; Jordan, 2003; Light, 2000). Restoration projects should be designed to emphasize and celebrate participation because this integrates humans into the ecosystem in ways that benefit both people and nature. For example, Eric Higgs (2003) says:

[S]ocial engagement is a vital part of restoration, not merely an afterthought.... restoration must be conceived in a way that makes the connections between culture and ecology, people and place, prominent (p. 257).

Andrew Light (2000) puts the point this way:

In the end, though, those restoration projects that contain more public participation will be, all things considered, better than those that contain less (p. 178).

Such theorists are having an effect on restoration practice. According to The Society for Ecological Restoration International's Guidelines for Developing and Managing Ecological Restoration Projects “The restoration team should make every effort to involve local residents or other interested members of the public to participate in project planning and installation.” ${ }^{5}$ SER's proposed certification guidelines include knowledge of how to involve volunteer participants meaningfully in restoration projects.

On the surface, this approach to restoration seems at odds with the aims of wilderness preservation. The conflict seems to stem from the nature of each practice. Instead of minimizing the human presence in an area undergoing restoration, wilderness managers would be charged with amplifying it even when not required by the ecological goals. By engaging more volunteer participation, they would be

\footnotetext{
${ }^{5}$ Clewell, Andre et. al., Guidelines for Development and Managing Ecological Restoration Projects. June 24, 2000. Society for Ecological Restoration International. March 1, 2005.

<http://www.ser.org/content/guidelines_ecological_restoration.asp>
} 
actively encouraging manipulation of an area. If good restoration requires us to increase human manipulation and control of an area beyond what is strictly necessary to accomplish ecosystem goals, then it appears to violate the minimum tools principle which stipulates that managers should "apply only the MINIMUM tools, equipment, device, force, regulation, action of practice that will bring the desired result” (Hendee and Dawson, 2002, p. 201). Activities that violate this principle unnecessarily diminish wildness and arguably constitute a trammeling. Not all participatory restoration trammels an ecosystem - using volunteers to remove a few exotics might not do so - but it is hard to see how a view of good restoration that celebrates human manipulation of an ecosystem can be reconciled with an ideal of wilderness that minimizes the “imprint of man’s work” on the landscape.

Managers might adopt a compromise between the conflicting values, a mix of celebrating the human and hiding it, but the result is unlikely to satisfy either the participatory values or the wilderness values. Moreover, a compromise may diminish public support for both the restoration and the restored wilderness. ${ }^{6}$ If one does not adopt such a middle position, one must either (1) modify the norms for good restoration or (2) relax the constraints on wilderness activities. On the first approach, one would reject the traditional idea of wilderness where human impacts are minimized, and substitute a new vision of wilderness compatible with recognizing and celebrating the human dimensions of an area. This account of wilderness might go so far as to incorporate habitation and resource extraction by indigenous people as well as some mechanized transportation. ${ }^{7}$ A great deal of contemporary criticism of the wilderness idea supports such an approach for reasons that go far beyond the puzzle at issue here (Callicott, 1991; Cronon, 1995). On the second approach, one would adopt a more complex view of restoration that minimizes human agency in those areas designated as "wilderness" while celebrating human agency in other areas, e.g. urban restoration. On this view, context should shape the standards by which projects are evaluated; we cannot achieve a single unified vision of good ecological restoration.

We will defend the latter response, but first we explore the reasons why the former seems appealing. Our discussion aims to show how the new vision for good restoration is part of a large scale shift in our understanding of human relations to nature, not just the idiosyncratic interest of a few democratic restorationists. The participation paradox is interesting precisely because it reveals the tension created

\footnotetext{
${ }^{6}$ See Cole (2000) for a parallel concern about wilderness managers compromising between the values of the natural and the wild.

${ }^{7}$ The Wild Foundation has articulated such a vision for wilderness areas in developing countries.
} 
by preserving a narrow concept of wilderness, while broadening our vision of other environmental practices like restoration. The same forces that drive the movement towards embedding humans meaningfully in landscapes tend to erode the constraints on wilderness management, leaving a broader range of options to be evaluated by managers and fewer uncontested reasons for choosing between the options.

We begin by outlining key moves in Eric Higgs' (2003) case for the first approach to the participation paradox. His Nature by Design is the most well-developed defense of the new view of restoration in the literature. Higgs explains in detail both why participation is important to restoration and how this new norm of participation is linked to our shifting views about the history of land use and our roles in ecosystems. Higgs takes wilderness as one of his central themes, beginning his book with a discussion of Jasper National Park in Canada, which he identifies as a "paradigm of wilderness." The Jasper ecosystem reflects significant prior human impacts. Rather than erasing these impacts, Higgs advocates restoration projects that preserve them, thus highlighting the human dimensions of the landscape. He is not thereby rejecting Jasper's status as wilderness, but rather abandoning the traditional idea of wilderness as untrammeled by humans.

After outlining Higgs' view of restoration, we turn to a critical assessment of those aspects of his restoration philosophy that create trouble for wilderness, in particular his guidelines regarding focal practice and wild design. We illustrate gaps in his arguments defending these guidelines and identify some dangers of implementing them in wilderness management. We also sketch a virtue-oriented defense of the traditional narrow definition of wilderness that is found in U.S. Wilderness Act. Critics of the traditional idea of wilderness rarely address the legal structures that undergird the preservation of wilderness, and thus they leave the practical implications of their proposals for management obscure. We trace the practical implications of our defense of traditional wilderness by showing how it limits and guides restoration practice. Specifically, we argue that restoration in wilderness should be guided by a healing metaphor that emphasizes values associated with the ecosystem itself, not the benefits that accrue to humans from the restoration process. We describe several ways in which the healing metaphor would fruitfully inform wilderness management policy. We contend, however, that often restoration is inadvisable in wilderness areas, because it compromises some core wilderness values without advancing other core values. We describe some of the conditions under which such restoration in wilderness is problematic. 


\section{The Changing Norms for Restoration}

Higgs' overview of the recent history of restoration definitions summarizes the motivations that led the Society for Ecological Restoration International (SER) toward an inclusive account of restoration that broadened the range of acceptable restoration goals and that emphasize participation by stakeholders and volunteers. This inclusive account stands in sharp contrast to a more restrictive view where the practioners, largely professionals and scientists, were valued less for their participation and more for the end product restoration. For example, early SER definitions of restoration focused on eliminating some human-caused damage from an ecosystem and returning the system to a pre-damage state. Such restorations would render the human impacts on the land less noticeable and hence increase the wilderness character of relatively wild landscapes. ${ }^{8}$ So understood, ecological restoration involves a short-term human modification of a system that aims to increase naturalness in the long run. Such definitions set goals that accord with the standards aims of wilderness management.

A central concern about this restrictive view of restoration is that it fails to encompass the variety of contexts in which restoration occurs and the range of meanings that it can have. In urban settings and in highly humanized rural landscapes like much of Europe, returning to an indigenous ecosystem often makes little sense. Still, land managers should act to ameliorate ecological damage. An inclusive account of ecological restoration embraces goals that retain human features of the landscape. ${ }^{9}$ Such an account also makes it easier to integrate humans into the ecosystem both during the restoration process and afterwards in maintaining the ecosystem. Arguably, this increases the overall success rate of projects. It also increases the creativity that restorationists can exhibit in the face of ecological damage and potentially broadens the appeal of restoration projects by permitting stakeholders more input into goal setting. Because it permits greater flexibility in the selection of restoration goals, a broader account also tends to increase the affordability of restoration, making it less exacting and more responsive to the constraints imposed by the context.

\footnotetext{
${ }^{8}$ See the SER 1990 definition of restoration: "Ecological restoration is the process of intentionally altering a site to establish a defined indigenous, historic ecosystem. The goal of the process is to emulate the structure, function diversity and dynamics of the specified ecosystem” (Higgs, 2003, 107).

${ }^{9}$ The 2002 SER definition exemplifies this kind of breadth: "Ecological restoration is the process of assisting the recovery of an ecosystem that has been degraded, damaged or destroyed.” Society for Ecological Restoration International Science \& Policy Working Group The SER International Primer on Ecological Restoration. Version 2, October 2004. March 1, 2005. < http://www.ser.org/content/ecological_restoration_primer.asp\#3>.
} 
An inclusive account of restoration permits the selection of goals that do not accord with traditional wilderness values, but it does not require such goals. Inclusive restoration practices are in tension with traditional wilderness preservation because they diminish constraints on human modification of the land while wilderness embodies strict constraints. Consequently, the motivations that drive the shift to more flexibility in restoration practices and more recognition of the human dimension of ecosystems would also push toward a less restrictive account of wilderness.

This shift involves receiving two standard goals of restoration, ecological integrity and historical fidelity, so that they fully reflect the insights that ecosystems are dynamic and that their pre-damage structures often reflect widespread influences of earlier human inhabitants. Higgs follows James Kay (1991) in characterizing “ecological integrity” in terms of the features of an intact ecosystem that enable that ecosystem to adjust appropriately to environmental change, including resiliency, elasticity, and stress response. An ecosystem with integrity maintains its organization in spite of the stresses typically visited upon the ecosystem. To restore integrity is not to return to a particular species assemblage, but to recreate a dynamic, functioning ecosystem. On this view, integrity is not the same as wholeness. For a project to count as good ecological restoration, it must recover a minimum of ecological integrity, but this minimum remains quite permissive. Ecological integrity need not be linked to a historic structure of an ecosystem; a mine reclamation project could return some minimal degree of integrity without using native species and still count as a good restoration.

According to Higgs, historical fidelity is "loyalty to predisturbance conditions, which may or may not involve exact reproduction...” (127). ${ }^{10}$ Since there are many ways of being loyal that diverge from past ecosystem structures, this constraint is also quite permissive. Higgs defends the historicity condition partly on ecological grounds; recovery of prior ecosystem structures may be the best way to promote integrity. But he also argues that the social values of nostalgia, narrative continuity and awareness of deep time play a central role in our desire for loyalty to past structures, and these values are often best expressed by seeking new ecosystem structures that are continuous with past ecosystems but that reflect current ecological and social realities. The permissive accounts of ecological integrity and historical fidelity reflect Higgs' vision of continuous landscape evolution resulting from the interplay of cultural and ecological factors. On this vision, restorationists should seek to move an ecosystem forward towards a structure that reflects what people value in the past, while responding to

\footnotetext{
${ }^{10}$ All page references are to Higgs (2003).
} 
changing situations. Managers should not try to move an ecosystem backwards toward some idealized “natural” structure. Public participation in restoration planning, design and execution may now become one of the dominant ways in which culture contributes to evolution of damaged ecosystems.

\section{Public Participation and Restoration as Focal Practice}

For those who advance the inclusive account of restoration, restoration activities are not just a means of ameliorating environmental damage, but a method for reconnecting humans with the rest of nature. Like others, Higgs sees the separation of culture and nature as the ultimate source of many environmental problems. Not only do people fail to see the effects of their actions on natural systems and lack the bonds with other ecosystem inhabitants that might support moral restraint, people also commodify nature. This tendency to see ecosystems as exchangeable goods priced in the market creates a danger for restoration. Higgs responds to this danger by requiring that good restoration involve what he calls “focal practice.”

A focal practice is an activity that "focuses" us on things that are deeply engaging and that integrates us into a system of meaning rooted in a history and place. It involves the development of skills and knowledge required to achieve excellence in the activity. Higgs borrows the concept from Albert Borgman's (1984) analysis of the losses associated with the rise of technologically oriented culture. Just as Borgman worries that technological advances can substitute commodities for meaningful objects, Higgs worries that restoration may become just one more technology in the toolbox for manipulating nature. If this happens, then a practice that might connect people to nature will instead further alienate people from nature.

Borgman identifies two fundamentally different ways people relate to objects. In the first, an object can be a meaningful center for an activity, one that embodies continuity with the past and "inspires commitment” to a project. For example, a wood stove can gather people to its warmth for conversation while it heats a room or a guitar can be the focal point for singing around a campfire. Borgman calls such objects "things" and sees their value largely as a function of the meanings they create for us. Things are the "features in our lives that permit the flourishing of social and bodily engagement with the world” (Higgs, 243). Alternatively, an object can be an interchangeable instrument that serves a specific function without engaging our attention, a mere "device” valued in terms of market pricing. Devices are mass-produced as efficiently as possible by experts; they rarely 
touch us deeply. When the oil furnace takes the place of the woodstove and CD's replace home-made music, life may become a little easier, but people lose the skills and knowledge required to use "things" like the stove and musical instruments. As a result, people lose meaningful connections to the world. Focal practices build relations to things, while technological practices fill people's lives with mere devices, enriching life temporarily but eliminating much of what makes life worthwhile.

Higgs worries unless restoration is understood as a focal practice, the field will become dominated by “technological restoration,” the application of the device paradigm to the practice of restoring ecosystems. Technological restoration is characterized by an emphasis on restoration technique, a professionalization of the practice, and an emphasis on efficiently producing a product. Higgs suggests that the movement towards certification for restoration professionals is a sign that the device paradigm is infiltrating the restoration community. This movement threatens to undermine the participation of volunteers in restorations which is necessary for restoration to meaningfully integrate humans into the landscape.

Higgs’ concern resonates with several critiques of restoration. Eric Katz (1992) charges that restoration creates artifacts, not natural systems, and thus it aims at the impossible. Robert Eliot (1982) worries that restoration can be used as an excuse to degrade ecosystems with the promise of replacing them later. Higgs fears that when people learn how to technologically replicate artificial ecosystems, they tend to lose the ability to appreciate the difference between the natural world and the artificial. People begin to see ecosystems as commodities, to be created or destroyed as suits their current desires. Moreover, if ecosystems are easily recreated, then there is little incentive to preserve wild ecosystems - especially when this conflicts with powerful economic interests. If ecosystems are treated as interchangeable "devices” that provide services for humans (and others), then people will not build bonds with their home ecosystems or develop the skills and knowledge necessary to re-inhabit these systems.

Thus, focal practice is not just an optional side benefit associated with restoration; rather, "social involvement though focal practices is a crucial factor in the success of ecological restoration” (Higgs, 222). ${ }^{11}$ The process of restoration becomes as important as the product, and the benefits to humans

\footnotetext{
${ }^{11}$ Strictly speaking, focal restoration need not involve volunteers. Mangers can engage with ecosystems as meaningful things. However, since the point of focal practice is meaningful engagement, focal restorations are better when more people are engaged in the activity.
} 
that accrue from meaningful relations to the land become as important as the values associated with ecological integrity and historical fidelity. Higgs' concern about technological restoration is well founded, and his emphasis on focal restoration is appropriate in many urban and rural contexts. However, when generalized to wilderness, his approach leads to the participation paradox. But do his arguments justify this generalization?

Perhaps the values served by focal restoration are sufficiently important that land managers and decision makers should compromise wilderness values in order to achieve them, but Higgs has not established that point. To do so, he would need to show that focal practice is the only way to avoid the problems associated with technological restoration and that all restoration should involve focal practice. Neither of these claims is defensible.

First, one can avoid the dangers of commodifying ecosystems without invoking focal practice. Moral practices involve treating other entities with respect and care, which is contrary to treating them as commodities, but it need not involve deep meaningful engagement with these entities. Indeed a moral practice can often involve two key characteristics of technological practice - professionalization and pursuit of efficiency. For example, medicine can be a moral practice. Doctors should treat their patients morally in the course of their activities, but doctors need not develop relationships with patients that are deeply meaningful and enrich the doctors' own lives. Doctors should respect their patients, and serve patients needs efficiently, any psychological benefits that doctors receive from such relationships should be secondary. Patients should not bear any of the additional costs of such benefits. Just as efficient, professional medicine need not turn the patient into a commodity, and efficient professional restoration need not turn an ecosystem into a commodity. According to ecocentrism, ecosystems should be treated as bearers of moral value, not as mere things. On this view, restoration is a moral practice, one that requires neither deep meaningful human engagement in the process nor volunteer participation to avoid the commodification of ecosystems.

Second, the arguments for focal restoration do not show that focal practice should be a criterion for good restoration. Like restoration, barn-raising can serve as a tremendous opportunity for focal practice, reconnecting people with each other and with buildings, but that does not show that one is required to meaningfully engage volunteers in building barns. Sometimes it is more important to just 
get the barn built quickly and with minimal fuss. In such cases, it is perfectly acceptable to contract with professional barn builders. The resulting barn may be a mere commodity, though one may also later build strong relationships with it that make it more of a "thing" than a device. Similarly, focal restoration may be a valuable, but non-essential component of successful restoration. If so, one should engage volunteers in focal restoration where this is easily achieved and where it does not compromise other important values, for example wilderness values. ${ }^{12}$

\section{Wild Design}

Higgs' fourth keystone concept of ecological restoration is wild design. The other three concepts are independent conditions for a successful restoration, but wild design is a metaphor that guides our thinking about restoration and incorporates the other three criteria. Higgs emphasizes design because he thinks that it serves as an antidote to the self-abnegation that characterizes some thinking about restoration.

...we need to acknowledge that restoration is fundamentally a design practice. Abnegation is not the proper path - we should celebrate and enlarge the skills and wisdom in restoration design, not bury it under a patina of ecological accuracy (274).

Where some people want to minimize the human element in restoration, Higgs wants to dramatize the fact that in restoration, we "inscribe our intelligence on the landscape” (270). Higgs defines "design” as an intentional activity that is carried out in a skillful or artistic way. Few would deny that restoration involves design in this sense. But Higgs goes on to say that a restored ecosystem is itself designed to meet the conditions of ecological integrity and historical fidelity, and moreover, that the process of restoration is designed so that it includes focal practice.

He realizes that such a view of restoration threatens to focus too much attention on human interests, when it is the ecosystem that should have priority. To emphasize this priority, he coins the phrase “wild design” which focuses on the "largely silent interests of ecosystems" and which recognizes that while human agency frames the projects, natural processes take over. Wild design aims to create the

\footnotetext{
12 The barn-raising objection applies to the arguments for public participation in Light (2000) and Jordan (2003). Showing that an important benefit can be derived from participation is insufficient to establish that participation should be a criterion for good restoration. One may respond that if one does not make it a criterion, then as a matter of fact the benefit will not be realized anywhere, because other considerations such as efficiency and quality control will inevitably favor more professionalized forms of restoration. This empirical claim is difficult to establish however given the range of other incentives available, including the satisfactions associated with the benefit itself.
} 
conditions under which an ecosystem can flourish through a process that engages participants meaningfully in exercising their skills and knowledge.

We agree that restorationists should acknowledge the intentional aspects of their practice because this encourages acting responsibly. But when Higgs insists that the metaphor of design should guide our thinking about restoration, he implies that restoration involves a significant amount of control and that it imposes human intentions on nature and on the human/nature interaction. The metaphor of design involves more than intention, skill and creativity, because many intentional activities done with skill and creativity do not seem appropriately characterized as design. For example, in jazz improvisation, a musician may exhibit considerable skill on an instrument and creativity in her ability to respond and improvise within a setting. Still, few would say that a jazz improvisation is designed, and even fewer would talk of designing the human/jazz experience - the relationship between the audience and the music. Jazz improvisation exhibits too much spontaneity and responsiveness to other musicians to be appropriately characterized as designed. Similarly in trauma surgery, a doctor may have a plan, but we do not typically speak of designing the surgery, for design connotes more control and imposition of human intention on its subject than is warranted in trauma surgery. ${ }^{13}$

If we can be both intentional and skillful without necessarily engaging in design, then why emphasize design in restoration? We believe that Higgs’ attraction to the design metaphor is motivated by his desire to craft restoration processes so they include focal practice. He emphasizes the dimension of the modern design movement that incorporates the experience of the person using the product into its design. In describing the design of a desk he says

[I]t is not the workstation per se that is designed, but the user's experience with the workstation... Well beyond ergonomics, experience is now modeled and designed to achieve specific human-centered goals.... (277).

Wild design reflects this movement towards an emphasis on the interface between a product and those who use it. One designs the experience that the human has with the ecosystem during the process of restoration, -- one designs the human/ecosystem interaction.

\footnotetext{
13 In plastic surgery, design is an apt metaphor precisely because it is less spontaneous and adaptive.
} 
This emphasis on designing the restoration experience may appear to soften the concern that design is incompatible with the "untrammeled" criterion of wilderness. Even though Higgs does talk about designing the ecosystem itself, which would seem to trammel it, his emphasis is on the restoration experience. But this leads to a different problem. It seems to put undue weight on the human experience. Wilderness is precisely where we should aim at self-abnegation, especially when we must engage in activities that manipulate the ecosystem. Celebrating human agency is inappropriate in areas where natural processes are supposed to dominate. It is also dangerous, for the "largely silent interests" of ecosystems are likely to be swamped by exuberant voices of human interests.

Presuming for the moment that we can make sense of “the interests of ecosystems” or at least nature’s intrinsic value, we can ask how these should be balanced with human interests. ${ }^{14}$ In most forms of land use, e.g. agriculture, human interests dominate and these structure ecosystems. Wilderness provides an opportunity for the interests of ecosystems to dominate. Even though human interests in recreation and ecosystem services played a significant role in early justifications of wilderness, biocentric approaches to wilderness management have become increasingly prevalent (Hendee and Dawson 2002). Our understanding of what is good for ecosystems is limited, however, and often ecosystem values are less salient than pressing human interests. The appeal to wild design does little to protect against the domination of human interests in restoration, especially as these are reflected in decisions about which members of an ecosystem to benefit and which ways of integrating humans into the ecosystem best reflect fidelity to a past. The design metaphor may be especially useful for restoration projects in urban areas, where integrating humans into ecosystems serves important educational, ecological and psychological goals, but we should be wary of generalizing across the contexts where restoration occurs. The primary goals associated with wilderness designation seem at odds with the design metaphor.

\section{Which Wilderness to Restore}

Some of these objections to emphasizing design and focal practice in wilderness restoration can be avoided by weakening the concept of wilderness and the associated constraints on actions in wilderness. Echoing Cronon (1995) and Callicott (1991), Higgs derides the traditional view of

\footnotetext{
${ }^{14}$ Serious problems stand in the way of literal identification of ecosystem interest (Varner, 1998). We use this phrase as shorthand for those ecosystem values that are not mere means to other human ends and that would guide biocentric or ecocentric management.
} 
wilderness that is ensconced in the U.S. Wilderness Act of 1964. He is particularly concerned about its alleged presumption that wildernesses are areas where the imprint of human activity is “substantially unnoticeable.” In Canada’s Jasper National Park anthropogenic burning, valley farming, trapping, fish stocking and tourism have significantly shaped the landscape, leaving a mosaic of meadows and forest in the valley areas. As a result of fire suppression, the crown canopy is more closed and the meadows are much diminished. In this "paradigm of wilderness," he defends a management regime that uses controlled burns to open the meadows and return the mosaic characteristic of the earlier human occupation. He criticizes "natural regulation” management policies for leading to further degradation of the ecosystem and for their failure to recognize the human history of the area. On this view, using volunteers in ways that leave distinctive marks on ecosystems should not count as a violation of the appropriate constraints on wilderness management since wilderness management should reflect both past and present engagement of people with the ecosystem. Higgs' claims about wilderness restoration in Jasper require a transformation of the idea of wilderness so it is “... not about the abolition of people, but about good ways of working with people in a natural setting...”(40). ${ }^{15}$

Other common arguments bolster his case. Not only is the goal of preserving traditional wilderness historically suspect, it is also metaphysically and ecologically problematic. Higgs maintains that wilderness preservation presupposes an ontological dualism between humans and nature that is indefensible in the light of modern evolutionary theory. He also worries that the tradition of wilderness preservation fundamentally isolates these natural sanctuaries from surrounding humanized lands, creating "a set of highly fortified islands of threatened wilderness surrounded by a sea of relatively heedless industrial activity” (41). Such areas could not be preserved except as highly managed “zoos.”

We will not rehearse the details of well-worn debates about the wilderness idea, but some defense of traditional wilderness is necessary to motivate our response to the participation paradox. ${ }^{16}$ We briefly review problems with Higgs' negative arguments, before turning to a positive argument that can guide

\footnotetext{
15 Higgs is concerned enough about the connotations of the term "wilderness" that he suggests talking instead about "wildness," which he takes to connote the unconventional, unconstrained and unpredictable. These characteristics of an area are more clearly compatible with reciprocal relationships between humans and the landscape. From a practical point of view, it makes little difference whether he retains the term "wilderness" and redefines it or substitutes a new term. In either case, he is shifting the constraints on management in areas now designated as wilderness in ways that permit more overt human alteration and control.

${ }^{16}$ See Callicott and Nelson (1998) for a review of the arguments on both sides of this debate.
} 
management choices. Past human modification of the land need not compromise present wilderness, for noticeable humanization can be washed out of a system by natural processes even if the system does not return to a predisturbance trajectory (Hettinger and Throop, 1999). The view that over time natural processes can reclaim an ecosystem is presupposed in the U.S. Eastern Wilderness Act of 1976. Most designated wildernesses in the eastern United States contain evident signs of farming, grazing and logging. Their capacity for regeneration is sufficiently great, however, that they are becoming places where natural processes are dominant. Such wilderness designation is forward-looking. Since what was not traditional wilderness can become so, arguments from history must either contain reasons for preserving signs of that history or for thinking they will never be eliminated. Sometimes important aesthetic, cultural or ecological reasons do support restoring human dimensions of a landscape, but from our perspective these are then reasons for not designating such an area as wilderness.

While some of roots of wilderness preservation did presuppose that humans were ontologically distinct from the rest of nature (Oelschlager, 1991), most contemporary arguments do not. We can value some areas in virtue of their wildness without making any metaphysical, evolutionary or ecological distinctions. In an industrialized world with a surfeit of human contrivances, we may simply want to have some places where we can escape the "all too human.” Many of our value distinctions do not rest on scientific or metaphysical distinctions, e.g. the value differences between friends and acquaintances, or between art and pornography. Such value differences can play key roles in our moral views and in public policy. The critic of wilderness “dualism” must show that there are no viable reasons for valuing ecosystems without humans - a daunting task, especially given able defenses of nonmetaphysical distinctions between human culture and the rest of nature (Rolston, 1994).

But are there positive reasons for retaining the traditional wilderness idea? The practical utility of wilderness designation as a means of protecting ecosystems might be enough to warrant its retention in the policy arena. The United States has protected 105,851,912 acres, (4.7\% of all land in the U.S.) in the National Wilderness Preservation System (Scott, 2004). The restrictions on use that characterize wilderness have prevented many kinds of degradation associated with resource extraction. Moreover, wilderness preservation continues to have widespread public support (Cordell et al., 2003; Scott, 2004). It is not clear that significant gains in utility would come from weakening constraints human activities in wilderness. Thus on purely practical grounds, it would seem reasonable to keep the traditional wilderness idea in the policy toolbox, even if the core values that it protects were unjustified preferences that many people just happen to have. We propose, however, that the core values of 
naturalness and wildness served by wilderness protection can be intersubjectively justified by reference to moral virtues that most of people applaud; these values are not mere preferences. This virtues justification suggests that we should place significant limits on wilderness restoration activities, including focal restoration.

Changing political fortunes have led advocates to explore new arguments for designating wilderness. They have placed increasing emphasis on the economic values and ecosystem services associated with wilderness, but less restrictive land designations, such as national conservation areas, would seem to protect these values equally well. We believe that ethical values play an important role in public support for wilderness, and that some of these do support wilderness designation in particular. The virtues defense for wilderness seems promising for three main reasons. First, recent studies indicate there is an increasing appreciation of non-use values associated with wilderness (Cordell et al., 2003). Many people believe that it is the existence of wilderness, not just our enjoyment of it, that is important. The appeal to virtues would partially explain why traditional wilderness is important even when it provides us with no self-interested benefits. Second, issues relating to character and ethics are increasingly salient, both in the national media and in the philosophical community. Virtue ethics has had a tremendous revival in the philosophical literature over the last twenty years (Hursthouse, 2002; Slote, 2003). Many people are more concerned about the characters of politicians than about the policies these politicians support. It is a small step to begin asking questions such as: What kind of a people do we wish to be and how should that image of our best selves be expressed in land use policy? One should not expect a single answer to such questions, of course, but the overlap between dominant answers may be sufficient to justify policy. Third, there seems to be widespread independent support for the virtues of humility, self-restraint, and altruism. These are not often referenced in connection with public policy or land use issues, but many people believe that they should embrace such virtues individually. The virtues argument for wilderness is not a substitute for other arguments, but it is an important supplement, one that is tightly linked to the defining characteristics of wilderness.

Allusions to relations between wilderness and virtues abound in the literature, but the virtues justification for wilderness has not been developed systematically. Howard Zahniser (1956), author of the U.S. Wilderness Act, says

We deeply need the humility to know ourselves as the dependent members of the great community of life, and this can be one of the spiritual benefits of a wilderness experience. ....to 
know the wilderness is to know a profound humility, to recognize our littleness, to sense dependence and interdependence, indebtedness and responsibility.

In a recent overview of the wilderness idea, TinaMarie Ekker (2004) urges that

Preserving wildness in wilderness requires that humans exercise humility and restraint, not dominance and control over the land, its creatures and its natural processes.

Dave Foreman (1998) maintains "No other challenge calls for self-restraint, generosity and humility more than Wilderness preservation.” Reed Noss (1991) claims that humility is one of four reasons for preserving wilderness. The alleged relationship between virtues and wilderness varies. Sometimes wilderness is said to beneficially shape our character; other times, wilderness preservation is an expression of our character. Both seem plausible, and they are mutually reinforcing. We are focusing on the latter claim, however, for it seems more compelling in an age when many wildernesses are overcrowded, and many people who support wilderness will never enter one.

Our rendition of the virtues justification for wilderness involves five key premises, each of which is potentially controversial. We provide a brief defense of each, recognizing that much work needs to be done to respond to the objections that naturally arise.

1. Humility, self-restraint and altruism are important, shared moral virtues.

2. Other things being equal, the shared moral virtues of a people should be expressed in the policies and actions of their country.

3. Having a virtue involves being disposed to express the virtue in contexts where one's most basic relationships are engaged.

4. A people's relationship with the land is a basic relationship

5. Wilderness preservation, as traditionally construed, is a paradigmatic expression of humility, self-restraint and altruism in a people's relation to the land. 
If U.S. citizens do widely share the core virtues, if there are no special reasons for refusing to express the virtues in governmental actions and if countervailing arguments against wilderness preservation fail, then the above line of reasoning will show that the U.S. should preserve wilderness. ${ }^{17}$

Before defending these five premises, we provide brief accounts of the relevant virtues. To have a virtue is to have a cluster of dispositions to think, feel and behave in certain ways. To approve a virtue is to believe that people ought to have such dispositions. The virtue of humility focuses on our limitations; it involves the acknowledgement of limits to one's knowledge, to one's self-importance, and to one's ability to control one’s environment (Compte-Sponville, 2001). ${ }^{18}$ A humble person is regularly aware of such limits and acts accordingly. With insufficient humility, one courts the dangers of hubris. Humility is sometimes associated with unwarranted self-deprecation, but this is a mistake. A humble person may have a healthy self-confidence, since the acknowledgement of limits often comes with the honest appraisal of one's successes. Modern cultures have experienced tremendous growth of knowledge and skills, so it is easy to forget limitations. Especially when it comes to manipulating ecosystems at large scales, our limits are quite marked. This explains the connection commonly drawn between humility and awareness of environmental problems. Humility is a particularly important virtue in times when limits are obscured and actions can have dramatic long term consequences.

Self-restraint and the associated virtue of moderation were clustered under the medieval virtue of “Temperance.” We ${ }^{19}$ appreciate temperance because we know our tendencies to overreach, to grasp for more than we need or can handle. The latter term has acquired a range of unfortunate connotations, but it captures key features of our moral world. Since our desires outrun our genuine interests, we will not flourish without restraining our actions. Moreover, acting on our immediate desires would often

\footnotetext{
${ }^{17}$ By itself, such reasoning does not tell us anything about how much wilderness should be preserved. That will depend on the potential areas suitable for wilderness designation and the need for alternative land uses.

${ }^{18}$ More work has been done on humility than any other environmental virtue, probably because hubris is thought to be the vice most responsible for our environmental destruction. Thomas Hill (1983) argues that our appreciation for the virtue of humility explains our discomfort with the destruction of natural systems and with a wholly resource-oriented approach to nature. Geoffrey Frasz (1993) further develops and corrects Hill's treatment of humility. Robert Sparrow (1999) develops a critique of terraforming Mars and other planets based entirely on the environmental vices that such activity demonstrates; hubris being one of these. A good deal of work remains to be done in both defending humility as an environmental virtue and drawing out the consequences of the virtue for wilderness preservation and other forms of land use. We further develop our treatment of the environmental virtues in Throop and Purdom (unpublished).

${ }^{19}$ Throughout the discussion of the virtues argument, "we" is used to designate our audience and hopefully many others living in developed countries, such as the U.S. and Canada.
} 
cause unjustified harm to others. The dispositions to recognize when we have had enough and to stop when inclined to go forward are central to the virtue of self-restraint. ${ }^{20}$ Greed and gluttony are among the corresponding vices. As our power to satisfy our desires increases, we must be more vigilant regarding self-restraint, for we cannot count on the fear of frustrated desires to motivate us. In a society devoted to consumption, the need for such vigilance is further increased, though its recognition is often belated. Humility and self-restraint are mutually reinforcing virtues, as both constrain our enthusiasms.

Western virtues traditions talk of charity and benevolence, rather than altruism. These may bear on wilderness preservation, but altruism captures more clearly the core idea of having dispositions to promote values associated with others, even when this conflicts with the pursuit of our own welfare. Contrary to the image of the rationally self-interested Homo economicus, most of us think we should sometimes sacrifice our interests for children, for friends, for fellow citizens and for members of other species. Our actions frequently reflect this, as do our appraisals of others. (Frank, 2003). Western cultures have not cultivated the habit of altruism with respect to natural communities, but arguments for expanding the range of those who are morally considerable make limiting our altruistic dispositions to humans increasingly problematic.

Other common virtues also support wilderness preservation. Humility, self-restraint and altruism are sufficient, however, to create a strong presumption in favor of traditional wilderness preservation. Most of us aspire to have these virtues to some degree, and we believe that we have good reasons to do so. On one plausible theory, these reasons ultimately involve showing that the virtues cohere with our knowledge of facts, including facts about the kinds of being we are, and with our considered moral intuitions. ${ }^{21}$

Even if we have such justification, it does not follow that we should adopt policies based upon them. One may think certain virtues are only appropriate to individual behavior, not collective behavior. The burden of proof lies on one who holds such a position regarding widely shared moral views, however, for it seems reasonable for a people to use democratic procedures to express their basic moral values in law as long as this does not violate the rights of others. Lobbyists and land managers, among many

\footnotetext{
${ }^{20}$ Bill McKibben's recent book Enough (2003) explores a variety of reason why we should exhibit self-restraint in the development of technologies such as germ line genetic engineering. Although he does not call self-restraint a virtue, the book can be read as a sustained defense of this virtue.
} 
others, often resist explicit appeal to ethics in justifying law and policy. They may be concerned about “legislating morality” or about ethical views being idiosyncratic, ungrounded or biased. Some of this resistance results from the legacy of positivism which left many thinking that ethics is mere expression of emotion, and some results from a history of unfortunate attempts by a minority to impose their ethical views on an unwilling majority, as in the prohibition movement. But much legislation and policy is grounded in shared ethical views, for example, the Americans with Disabilities Act and the Civil Rights Act. We have no compunctions about this source of justification if the views are widely enough accepted, and they do not merely reflect a specific ideal of the good life. ${ }^{22}$

The appeal to virtues, as opposed to moral rules or utilitarian calculations, should make no difference in the legitimacy of the moral reasons for legislation and policy. One may be squeamish about legislating that we teach certain virtues or require that they be accepted, but this is wholly independent of whether we should collectively adopt other kinds of laws based on virtues that are widely shared. Humility, self-restraint and altruism do not seem associated with an idiosyncratic view of the good life, unless they are taken to extremes as in asceticism. In the absence of good reasons for avoiding justifications involving such virtues, we should use them in contexts that demand their expression. But where and when must we express such virtues?

To have a virtue involves being disposed to act on the virtue in at least some contexts where one's most basic relationships are engaged; we will call these "crucial contexts.” A basic relationship is plays a central role in one's life. In most cases, one's relations with one's family are basic in the relevant sense, so one cannot be said to have the virtue of altruism, for example, if one does not express it in the context of the family. One of the key lessons of environmental history is that a people's relationship with the land is a basic relationship. A culture is shaped by the ecosystems on which it depends, as it in turn alters them to meet its needs (Leopold, 1949; Worster, 1992; Cronon, 1983; Diamond, 1999). This may be more apparent to agricultural peoples, than to urbanites, but it is no less true. Urban cultures depend on complex relations to lands that are often quite distant from its citizens, so the interdependencies are less visible, but the land relationships remain tremendously important. Many technologies also render relations to the land less salient, but in most cases, technologies merely shift the ways in which people are dependent on ecosystems.

${ }^{21}$ The coherence theory of moral justification has been developed and defended in Sayre-McCord (1996). 
If land relationships are basic, then land use issues create crucial contexts for the expression of humility, temperance and altruism. To have these virtues, a people must exercise them in some of their actions regarding the land. This leaves many puzzles. For example, how can one be altruistic towards an ecosystem? One can promote intrinsic values associated with the land and the welfare of sentient organisms that dwell there. But what values and how should we promote the welfare of wild animals? ${ }^{23}$ Notoriously, virtues do not tell us exactly what to do (Louden, 1984). Indeed, the "wilderness" virtues can be expressed in a variety of land uses. Temperance can lead us to sustainable land uses, like selective logging and organic agriculture. Altruism finds expression in intensive ecological restoration, and humility is reflected in adaptive management and in the adoption of a plurality of management regimes. Taken individually these virtues do not provide strong motivation for wilderness preservation.

When these core virtues are embodied together, however, their paradigmatic expression in relation to land is wilderness preservation. When concern for the welfare of members of the land community is combined with a recognition of our ignorance about how to engineer systems to promote welfare and a restraint of our impulses to manipulate land to satisfy our own desires, the result is to reserve some land where natural processes dominate. Often we are justified in pursuing our own interests by modifying the land, but if we are altruistic we should restrain this impulse in some places to let others flourish who do not benefit from human contact. Often we do know how to enhance ecosystem values or to benefit members of threatened species. But if we are humble, we are also aware of our tendency to err in judgments about what is good for an ecosystem and to make mistakes in attempting to help others. Where we restrain both self-interested motives and our urge to improve nature, because of a recognition of our limits, we create an opening for wilderness.

In at least some places we should manifest the virtues of humility, self-restraint and altruism conjointly; they are mutually reinforcing and taken together they express a coherent ethical orientation. As individuals, we sometimes encounter situations where concern for another's plight requires us to simply "let her/him be" despite our inclinations to do otherwise, because we understand the limits of

\footnotetext{
${ }^{22}$ Some have defended wilderness preservation because it protects the interests that a minority has in non-mechanical recreation and solitude on public lands. This more self-serving argument can also be linked to virtues, but in this case the virtues are taken to features of a particular vision of the good life, not general public virtues.

${ }^{23}$ To fully answer such questions, one would need to develop an ecocentric ethic. Here we presuppose that some version of ecocentrism is defensible, but we need take no stand on its details in the virtues defense of wilderness.
} 
our abilities to ameliorate the situation. Analogously, wilderness preservation is an expression of our collective recognition that we should just "let nature be” in some places.

This virtues argument supports the traditional view of wilderness, because it partially explains why we should intrinsically value ecosystems that are relatively natural and wild. These are both characteristics of regions where we have "let nature be” for a while. It does not support them equally however, for preserving wildness is the more direct expression of humility and self-restraint.

Preserving naturalness is derivative, since it characterizes the way an ecosystem would be if we had “let it be.” We can restore naturalness through our actions, but we often best recover wildness through inaction.

If we retain the traditional idea of wilderness, then we must address the participation paradox by limiting the scope of volunteer-based restoration. Wilderness restoration becomes a special situation where volunteers should be used only when they are necessary to achieve a legitimate restoration goal. The benefits they derive from such activities should be afterthoughts, and "self-abnegation” should be the watchword for restoration activities. How, then, should we think about restoration in wilderness?

\section{Public Virtue and Wilderness Restoration Practice}

If the virtues argument plays a significant role in the justification of wilderness preservation, then it should also help to guide managers in decisions about restoration. It has implications for both how one restores and when restoration is warranted. Often one cannot determine when wilderness restoration is appropriate until one specifies a potential goal and assesses what means would be required in order for it to be successful. If the means necessary to achieve a potential goal involves too much long-term control, then one may need to change the goal or refuse to restore.

The goals of wilderness restoration are typically identified in terms of endpoints that would increase naturalness value, but managers still have options regarding which reference conditions to select for a system and how much naturalness to restore. Given the virtues argument, managers should select from among these options the one that can be achieved using the least controlling means unless there are extenuating circumstances. Because one cannot quantify the degree of control associated with a particular restoration technique, managers must rely on comparative judgments about the duration, spatial extent, degree of mechanization and amount of force in different restoration methods. They 
may be aided by a metaphor for wilderness restoration rather different than Higgs' wild design. The metaphor of restoration as healing seems to incorporate the virtues discussed above, while also developing a standard theme in restoration theory. ${ }^{24}$

In the role of healer, doctors aim to promote the welfare of others; their own interests in making a living, gaining personal satisfaction or being engaged in meaningful activity are secondary and incidental to the practice. The healing model shifts emphasis away from the doctor's activity and focuses us on the goal of eliminating a specific illness (or disturbance) and allowing the system's natural processes to take over. Rolston (1994) likens ecological restoration to setting a broken bone; a healer resets the trajectory, but nature does most of the work. In such cases, the system remains autonomous, or untrammeled, once the treatment is completed. A good healer exercises self-restraint by using the least invasive means of achieving health, even where other means would accomplish additional personal or scientific goals. Often however, these means involve advanced technologies and they may be highly invasive, as in surgery. Professionals should wield such healing technologies, not volunteers and amateurs, and they should use the most efficient methods of returning a system to a predisturbance trajectory. A professional is good at "listening” to the system and responding appropriately; this calls for humility.

In general, one does not involve others directly in the healing process unless such participation speeds healing. A patient's community members are not encouraged to participate in his appendectomy, just because such participation will enhance their relationship with either the patient or with the human body. In some cases, social support does play an important role in a cure, but this is determined by the patient's condition and by the context, not by the interests of the community at large in avoiding technological medical practice. To be sure, such a healing practice could degenerate into a merely technical practice that treats patients as commodities; some worry that HMO's lead in this direction. The answer to this is not more focal practice, however. It is ensuring that medicine is a moral practice that treats patients as ends in themselves.

\footnotetext{
24 The healing metaphor has often been used to characterize restoration (Nilsen, 1991; Mills, 1995; Clewell,, 2000). It is usually applied to restoration in all contexts, though we suggest it is particularly appropriate to wilderness. There are many ways to approach healing, some quite at odds with the idealized vision we sketch. The metaphor is not meant to apply all of the norms of contemporary medical practice to ecosystems. Several features of the healing metaphor raise difficult problems that are well beyond the scope of this paper - problems about how to characterize ecosystem health, about the subjectivity of judgments of health and about the applicability of treatment paradigms associated with medical practice.
} 
The healing metaphor highlights several norms for wilderness restoration. First, managers should allow the system to heal itself to the greatest extent possible. Second, projects should seek short term interventions, even if these may be more aggressive than longer term restorations. Third, projects should engage volunteers only where they are necessary to achieve a goal in the most efficient way. For example, the elimination of exotic mountain goats from Olympic National Park wilderness areas has been proposed to help restore sub-alpine regions (Throop, 2000). The use of professional sharpshooters would minimize the duration and impact of the project. This seems preferable to longterm trapping projects or focal practice involving amateur hunters outside the parklands.

Sometimes, the least invasive restoration methods involve short-term use of mechanical devices rather than longer-term non-mechanized volunteer labor. The restoration of herbaceous ground cover in Bandelier Wilderness required thinning of piñon-juniper forest. The project began by using volunteers to cut juniper with hand saws, but this approach was superceded by chainsaw wielding professionals (Sydoriak, et. al. 2000). The result does trammel the ecosystem in the short term, but if it serves critical ecological and archeological goals in the least trammeling way; it can be an appropriate kind of “ecosystem surgery.”

The healing metaphor leaves unanswered many questions about the choice of means to achieve wilderness restoration goals, but it provides a promising way of thinking about such choices. The norms that it suggests for wilderness restoration may be overridden by other considerations including cost, social pressures and special ecological considerations, e.g. the protection of an endangered species. But if the virtues argument is a central motivation for preserving wilderness, then the burden of proof should lie on those supporting more participatory restoration. For example, if economic considerations are driving the extensive use of volunteers in a project when other means better fit core wilderness values, then one needs special arguments against accepting a higher cost or for the loss of wilderness value. The burden of these arguments should be considerable, given the scarcity of wilderness.

When should managers restore a degraded wilderness and when should they just let it evolve on its own? As goals and means are developed for a potential project, managers must decide whether these are compatible with wilderness designation. If not, then they must decide whether there are compelling reasons to pursue the restoration anyway. The virtues justification, with its emphasis on wildness, suggests that restoration in wilderness should be rather limited. Moreover, if as Higgs and 
others argue, few areas were unaltered by indigenous peoples, then naturalness is hard to identify and preserve. This tends to elevate further the significance of wildness value by comparison.

Consequently, it lends support to stronger restrictions on restoration and suggests that often we should allow an ecosystem to respond to human caused degradation by adopting a new trajectory.

Some wilderness restoration is justified though. Where the ecosystem approximated a primeval state at the time of wilderness designation or where early human influences were sufficiently remote in time that they have washed out of the system, there is a relatively natural state to serve as a goal. Sometimes managers have a large amount of knowledge about the ecosystem processes and structures that characterized that natural state and about how these could be restored in a relatively short-term project. If so, then they do not contravene humility and self-restraint by pursuing restoration. Altruism will justify a project if it can significantly enhance some ecosystem value. These conditions often hold where mangers are repairing damage from recreational overuse or where they are removing limited populations of exotics species.

By contrast, where ecosystems have been heavily modified by humans for an extended period of time or where the knowledge and skills required to restore a natural state are quite limited, the case for restoration is significantly diminished. Well-intentioned managers frequently over-estimate their abilities and the result is that restoration projects have unintended consequences that reduce both naturalness and wildness. Humility and self-restraint should motivate managers to proceed with caution in wilderness areas, and to avoid the rush to take some action that might address an ecological problem. In contexts where ecosystems are characterized by significant long-term anthropogenic influences, e.g. systems that reflect significant burning by indigenous peoples, we usually do not know what a fully natural trajectory would involve. Moreover, often such ecosystems must be continuously managed to preserve that structure. This compromises wildness value, without increasing naturalness. Wildness is usually enhanced by letting such an ecosystem continue on its own current trajectory. Ultimately letting it go will contribute to its naturalness as the human influences are washed out of the system. Thus, it seems, the burden of proof lies heavily on those who wish to restore such systems. As in the case of Jasper National Park, there may be historical, cultural or ecological reasons to restore, but these are reasons for managing the area as something other than wilderness.

Some may object that we are unduly weighting the virtues argument for wilderness. After all, there are other arguments that may have quite different implications for management. For example, the 
biodiversity argument used extensively by the Wildlands Project would seem to favor naturalness over wildness in management decisions. If the aim of wilderness is to protect our native flora and fauna by providing a place where all of the natural processes that maintain them occur, including large scale disturbances, then wilderness should be managed to recreate natural systems no matter what the impact on wildness.

This biodiversity objection derives much of its plausibility from an ambiguity in the goal it seeks to achieve in wilderness. If that goal is providing a place where other species can flourish without interference from humans, then the biodiversity argument is a version of the virtues justification and it supports an emphasis on wildness. If, on the other hand, the goal is preserving the full compliment of native biodiversity in its historical distributions, then traditional wilderness is probably not the right means to achieve the goal. That goal is best served in many areas by active continuous management using mechanized transportation and other means antithetical to wilderness. So construed, the biodiversity argument does favor naturalness, but it supports less restrictive designations like national conservation areas, rather than wilderness. ${ }^{25}$

\section{Conclusion}

We have identified a "paradox" that results from conflicting trends in ecological restoration and wilderness preservation. Many restorationists have sought to design restoration projects to integrate people fruitfully into a landscape, reconnecting volunteers with nature in rich and meaningful ways. Some theorists have argued that such design should be a requirement for successful restoration. One implication of this movement is that the human dimensions of restoration are emphasized and celebrated. On the traditional conception of wilderness, human impacts on an area are minimized, and visitors celebrate the mysteries of the more-than-human natural world. Higgs resolved this paradox by rejecting the traditional idea of wilderness and substituting a conception that includes humans as full participants in the shaping of ecosystem processes. While he is motivated in part by the real threat of commercialized restoration, his solution of focal practice is not the only way to avoid the threat. Moreover, it is particularly dangerous when applied to wilderness. We support the emphasis on focal restoration in populated areas. However, we caution against over-generalizing this model. The

${ }^{25}$ Many arguments for wilderness, such as recreational arguments, are neutral with respect to the weighting of wildness and naturalness. We believe that those that would emphasize naturalness are subject to the problems we have briefly sketched for the biodiversity argument. 
reasons for rejecting the traditional wilderness idea are far from compelling, and there are strong practical and theoretical reasons for retaining it.

Our resolution of the paradox involves placing significant limits on restoration activities - limits on when restoration is justified and on how volunteers can be used. These limits must be contextually interpreted. What is legitimate in a small, heavily-used wilderness may not be appropriate in more remote large wilderness. Restoration in wilderness should be guided by the core justifications for wilderness preservation, since these help us to interpret and prioritize the constraints embedded in the U.S. Wilderness Act and related legislation. Such justifications change over time. We suggest that the virtues justification should play an increasingly important role in motivating wilderness preservation, and we show how that justification might be developed and defended. The virtues justification promises to guide wilderness management in part through a healing metaphor for restoration. Much human behavior is shaped by powerful metaphors that help us to operationalize norms for behavior. Higgs' metaphor of design is particularly dangerous when applied to wilderness restoration. A healing metaphor seems more fruitful, providing it is informed by the humility, self restraint and altruism.

The conflict between wilderness preservation and participatory restoration is a manifestation of the collision between two visions of the proper human relationship with nature. One sees humans as integral parts of nature - "plain members of the biotic community." It locates the root of environmental problems in our separation from nature, and identifies our major challenge as sustainably integrating members of urban cultures into ecosystems. The other vision sees culture as fundamentally different from nature and appropriately kept apart, at least in some areas. For this second vision, the source of environmental problems is a lack of balance between natural and cultural values, manifested in rampant manipulation of nature and in the hubris of faith in technological fixes. The challenge is to redress the imbalance by motivating self-restraint and elevating our appreciation of nature.

It is easy to see why wilderness preservation might be a battleground between these two visions, but it is less clear why one must choose between them. Both embody important insights, which are not mutually exclusive. Our problems probably have multiple roots. We should both integrate humans into nature and preserve some nature apart. Participatory restoration is an excellent way of achieving the former, just as traditional wilderness eloquently expresses the latter. The participation paradox arises 
from an undue emphasis on the first of these visions and a failure to contextualize its implications. Our solution attempts to restore the balance. 


\section{References}

Aplet, G.H. 1999. On the nature of wilderness: exploring what wilderness really protections. Denver University Law Review. 76: 347-367.

Borgmann, A. 1984. Technology and the Character of Contemporary Life. Chicago: University of Chicago Press.

Callicott, B. J. 1991. The Wilderness Idea Revisited: The Sustainable Development Alternative. The Environmental Professional 13:235-47.

Callicott, J B. and M. Nelson. 1998. The Great New Wilderness Debate. Athens, Georgia: University of Georgia Press.

Clewell, A. 2000. Restoring for Natural Authenticity. Ecological Restoration. 18:216-17.

Cole, D. N. 1995. Ecological Manipulation in Wilderness - An Emerging Management Dilemma. International Journal of Wilderness,

Cole, D. N. 2000. The Paradox of the Primeval: Ecological Restoration in Wilderness. Ecological Restoration. 18(2): 77-86.

Cole, D. N. 2003. Agency Policy and the Resolution of Wilderness Stewardship Dilemmas. USDA Forest Service Proceedings RMRS-P-15-Vol.4.

Cole, D. N., and P. B. Landres. 1996. Threats to Wilderness Ecosystems: Impacts and Research Needs. Ecological Applications 6(1): 168-184.

Comte-Sponville, A. 2001. (translated by K. Temerson)., A Small Treatise on the Great Virtues. New York: Henry Holt \& Co.

Cordell, H. K. et al. 2003. Is the Public Viewpoint of Wilderness Shifting? International Jouranl of Wilderness. 9: 27-32. 
Cronon, W. 1983. Changes in the Land.

Cronon, W. 1995. The Trouble with Wilderness; or Getting Back to the Wrong Nature, in W. Cronon, ed., Uncommon Ground: Toward Reinventing Nature, New York: Norton.

Daly, H. 1996 Beyond Growth. Boston: Beacon Press.

Egan, D. 2004. Ecological Restoration. 22:

Diamond, J. 1999. Guns, Germs and Steel. New York: W. W. Norton and Co.

Egan, D. 1990. Historical Initiatives in Ecological Restoration. Restoration and Management Notes 8(2): 83.

Ekker, T. 2004.The Idea of Wilderness. International Journal of Wilderness. 10:15-17.

Eliot, R. 1982. Faking Nature. Inquiry 25: 81-93.

Foreman, D. 1998. Wilderness Areas are for Real. in Callicott, B. and Nelson, M. 1998.

Frank, R. 2003. What Price the Moral High Ground?: Ethical Dilemmas in Competitive Environments. Princeton, NJ: Princeton University Press.

Franz, G. B. 1993. Environmental Virtue Ethics: A New Direction for Environmental Ethics. Environmental Ethics 15(3): 259-274.

Glicksman, R. L., and G.C. Coggins, Symposium: Wilderness Act of 1964: Reflections, Applications and Prediction: Content: 1. Reflection and Prediction: Wilderness in Context. Denver University Law Review, 76: 383.

Graber, D.M. 2003. Ecological Restoration in Wilderness: Natural versus Wild in National Park Service Wilderness. The George Wright Forum. 20: 34-41. 
Hendee, J. C. and C. P. Dawson. 2002. Wilderness Management: Stewardship and Protection of Resources and Values. Third Ed. Golden, Colorado: Fulcrum Publishing.

Hettinger, N. and W. Throop. 1999. Refocusing Ecocentrism, Environmental Ethics. 21(1) 3-21.

Hill, T. E., Jr. 1983. Ideals of Human Excellence and Preserving Natural Environments. Environmental Ethics 5:211-24.

Higgs, E. 2003. Nature by Design. Cambridge: The MIT Press.

Hursthouse, R. 2002. On Virtue Ethics. New York: Oxford University Press.

Jordan, W. R. 2003. The Sunflower Forest: Ecological Restoration and the New Communion with Nature. Berkley, Los Angeles, London: University of California Press.

Katz, E. 1996. The Big Lie: Human Restoration of Nature. Research in Philosophy and Technology 12: 231-243.

Kay, J.J. 1991. A Non-Equilibrium Thermodynamics Framework for Discussing Ecosystem Integrity. Environmental Management. 15:483-495.

Landres, P.B., P. Morgan and F.J. Swanson. 1999. Overview of the use of natural variability concepts in managing ecological systems. Ecological Applications 9:1179-1188.

Leopold, A.1949. A Sand County Almanac. New York: Oxford University Press.

Light, A. 2000. Restoration, the Value or Participation, and the Risks of Professionalization, in P.H. Gobster and R.B. Hull, eds.. Restoring Nature: Perspectives from the Social Sciences and Humanities, 163-184. Washington, D.C.: Island Press.

Louden, R. 1984. On Some Vices and Virtue Ethics, American Philosophical Quarterly. 21: 227-36. 
Mckibben, B. 2003. Enough: Staying Human in an Engineered Age. New York: Times Books.

Mills, S. 1995. In Service of the Wild. Boston: Beacon Press.

Nilsen, R. 1991. Helping Nature Heal: An Introduction to Environmental Restoration. Berkely, CA: Ten Speed Press.

Noss, R. 1991. Sustainability and Wilderness Conservation Biology. 5(1): 120-122.

Oelschlaeger, M. 1991. The Idea of Wilderness. New Haven and London: Yale University Press.

Rolston, H. 1994. Conserving Natural Value. New York. Columbia University Press.

Sayre-McCord, G. 1996. The Fundamental Appeal of Coherence in Moral Epistemology. in SinnottArmstrong, W. and Timmons, M. Moral Knowledge: New Readings in Moral Epistemology. New York: Oxford University Press.

Scott, D. 2004. The Wilderness Act at 40. International Journal of Wilderness. 10:8-14.

Slote, M. 2003. Morals from Motives. New York: Oxford University Press.

Sparrow, R. 1999. The Ethics of Terraforming. Environmental Ethics 21(3):226-245.

Sydoriak, C. A.; Allen, C. D.; Jacobs, B. F. 2000. Would ecological landscape restoration make the Bandelier Wilderness more or less of a wilderness? in Cole, D.N.; McCool, S.F.; Borrie, W.T.; O’Loughlin, J., comps. Wilderness science in a time of change conference - Volume 5; Wilderness Ecosystems, Threats and Management; May 23-27, 1999; Missoula, MT. RMRS-P015-Vol.-5. Ogden, UT: USDA, Forest Service: 209-215.

Throop, W. Eradicating the Aliens: Restoration and Exotic Species. in W. Throop (ed.) 2000. Environmental Restoration: Ethics, Theory, and Practice. New York: Humanity Books.

Throop, W. and Purdom, R. Why Wilderness Now? (unpublished manuscript). 
Turner, J. 1996 The Abstract Wild. Tucson, AZ: The University of Arizona Press.

The Wilderness Act of 1964, Public Law 88-577. $88^{\text {th }}$ Congress, S.4, (September 3, 1964).

Varner, G. 1998. In Nature's Interests: Interests, Animal Rights and Environmental Ethics. New York: Oxford University Press.

Worster, D. 1992. Rivers of Empire: Water, Aridity and the Growth of the American West. New York: Oxford University Press.

Zahniser, H. 1956. The Need for Wilderness Areas. Living Wilderness. 59:37-43. 